\title{
La controvertida postura de Luis Eduardo Nieto Arteta ante el marxismo
}

El marxismo, o al menos lo que comúnmente se entiende por él, como teoría política, económica, sociológica y filosófica ha experimentado en la historia de América Latina desde fines del siglo xix hasta nuestros días (Guadarrama, 1999, pp.1-72), como en otras latitudes, diversos modos de apropiación, cultivo y desarrollo.

Inicialmente a mediados del siglo XIX, en la propia Europa donde había germinado se le consideraba básicamente una teoría política revolucionaria articulada a una proyección ideológica de orientación socialista o comunista, y por tanto vinculada a diversas expresiones utópicas de ideas de tal género anteriormente profesadas, si bien se le distinguiría por la denominación que Engels le asignaría de socialismo científico. Injustamente se le emparentó con el anarquismo, dadas sus comunes críticas a la explotación de los trabajadores en el capitalismo y al papel del Estado como instrumento de dominación de la burguesía.

Los vaivenes en el reconocimiento político e intelectual de la significación del marxismo estaría articulado orgánicamente al surgimiento de los partidos socialdemócratas así como a la actividad de la Primera y la Segunda Internacional, consideradas como socialistas, pero en especial a 
las luchas de los trabajadores por conquistas sociales y económicas que alcanzaron por entonces una de sus mejores expresiones en la Comuna de París de 1871.

Con independencia de que el Manifiesto comunista y algunos artículos de Marx y Engels fueron publicados en español a fines del siglo xix, en la misma medida en que algunas de las principales obras de Marx, fundamentalmente El Capital, se fueron traduciendo a varios idiomas, comenzó a considerarse al marxismo básicamente como una teoría económica de profunda raigambre sociológica y política. De manera que solo una reducida elite intelectual latinoamericana que tuviera conocimiento del alemán, el inglés o el francés, podrían haber tenido acceso directo a la amplia obra de Marx y Engels, que hasta la actualidad se continúa publicando (y se puede encontrar disponible en: http://marxismocritico.files.wordpress.com/2012/10/mega. pdf). La traducción al español de El Capital realizada por el argentino Juan Justo en 1898, por supuesto que permitiría una mayor difusión de la misma en el ámbito latinoamericano.

Algo similar sucedería durante las dos primeras décadas del siglo xx en cuanto a la barrera idiomática con las obras de otros marxistas como Antonio Labriola, Karl Kautsky, Jorge Plejanov, Rosa Luxemburgo, Vladimir Lenin, León Trotsky, entre otros. Con el triunfo de la Revolución de Octubre en 1917 en Rusia y la gestación de la Tercera Internacional, identificada como Comunista (Komintern), —dada su ruptura con la política reformista de los partidos socialdemócrata-, que dio lugar el nacimiento de los partidos comunistas, la labor de traducción a varios idiomas propiciada por la naciente Unión Soviética, posibilitó que sectores más amplios de la población y no solo intelectuales, tuvieran acceso a algunas de las obras fundamentalmente de Marx, Engels y Lenin.

Sin embargo, al mismo tiempo con la intención divulgadora de lo que en tiempos de Stalin bautizarían inicialmente como marxismo-leninismo y poco tiempo después como marxismo-leninismo-stalinismo surgieron una serie de textos divulgadores de la teoría marxista, conocidos como manuales, elaborados por Bujarin, Deborin, Konstantinov, entre otros, que lamentablemente en lugar de contribuir a un mejor conocimiento de la concepción materialista de la historia, deformaron en gran medida las ideas originarias de sus gestores. A la vez promovieron el llamado materialismo dialéctico que había tenido su origen en una interpretación de Joseph Dietzgen y Jorge 
Plejanov de una idea de Engels. A esto se añadía el hecho de que las principales obras filosóficas de la juventud de Marx y Engels, habían permanecido ocultas en sus archivos y cuando se publicaron fueron tergiversados por el aparato político stalinista porque iban en contravía del experimento soviético de socialismo.

Las nuevas interpretaciones del marxismo que emergían en la teoría crítica de la Escuela de Frankfurt o en la filosofía de la praxis de Antonio Gramsci quedarían reducidas a pocos espacios intelectuales que tuvieran acceso a sus obras. De manera que el emergente marxismo occidental, caracterizado por Merlau Ponty que se diferenciaría notablemente de lo que Herbert Marcuse llamó marxismo soviético, no alcanzaría en América Latina en realidad una mayor difusión hasta la década de los años sesenta en los que el rumbo socialista de la Revolución Cubana tendría una especial significación para la región (Guadarrama, 1998. pp. 262-271).

Esta es la época en que las obras filosóficas de Marx y Engels como La sagrada familia, los Manuscritos económicos y filosóficos de 1844 y especialmente La ideología alemana, con las significativas Tesis sobre Feuerbach, entre otras, junto a la mayor difusión de las obras de Antonio Gramsci - pues ya se había iniciado desde los años cincuenta en Argentina- la perspectiva estructuralista del marxismo en Althusser (Guadarrama, 2007a. pp. 61-77) y las obras de los principales representantes de la primera generación de la Escuela de Frankfurt, Horkheimer, Adorno y Marcuse irían permeando el ambiente filosófico marxista latinoamericano no sin encontrar resistencia por parte de los cultivadores de la interpretación soviética del marxismo que alardeaba por poseer el exclusivo marxómetro oficial, para medir y determinar cuáles eran los más fieles continuadores del Prometeo de Tréveris. Marx nació en esta ciudad alemana y había sido un gran admirador del mitológico héroe griego.

De manera que durante la primera mitad del pasado siglo xx especialmente durante la década de los años treinta, cuarenta y mediados de los cincuenta en el que despliega su actividad intelectual Luis Eduardo Nieto Arteta, el ámbito cultural latinoamericano no disponía de esas nuevas fuentes y perspectivas de las obras de Marx y Engels en tanto prevalecían aquellas versiones e interpretaciones debidamente ajustadas por el aparato ideológico stalinista. 
Esos factores condicionarían significativamente la formación juvenil casi autodidacta, por lo menos en lo que relacionado con el estudio del marxismo de Nieto Arteta. De manera que cuando le declaraba en 1942 a Francisco Romero: "Mis estudios filosóficos y aún sociológicos se iniciaron con el marxismo" (Nieto, 1942). Por supuesto hay que cuestionarse a qué fuentes de esta teoría se estaba refiriendo. Esto puede explicar algunas de sus simplificaciones y extravíos en ella, independientemente que finalmente factores de carácter ideológico y político le distanciaran en el plano de actitud práctica del ideario socialista aproximándole al liberalismo, que no serán objeto del presente análisis.

\section{Según Gonzalo Cataño:}

Sus lecturas fueron, en general, las mismas de los demás integrantes del Grupo Marxista de Bogotá (1933-1934). Como ellos, partió de Engels, a quien empezó a leer en 1933, el Anti-Dühring sobre todo. Al lado de este compendio estaba Las cuestiones fundamentales del marxismo de Plejanov, una de las obras que más contribuyó a su formación intelectual: 'me descubrió una concepción del mundo que me suministró una respuesta adecuada a todos los problemas científicos y filosóficos'. A estos libros se añadieron las lecturas económicas poco frecuentes entre sus compañeros. Nieto fue uno de los pocos que hizo referencias directas a El capital y que lo empleó como fuente de inspiración en sus trabajos históricos. Este contacto inicial con la economía política incluyó a Rosa Luxemburgo, a quien se refería familiarmente como la genial 'Doña Rosa' y de la cual se decía su discípulo. (Cataño, 2013, p. 98).

Resultan significativas sus referencias a la obra de la destacada revolucionaria polaca en relación con el análisis del imperialismo (Nieto, 2004, p. 11). ${ }^{82}$

82 "Como, además, Nieto Arteta tenía una formación marxista (estaba muy familiarizado con la teoría del imperialismo de Rosa Luxemburgo) y se interesaba en las relaciones entre países capitalistas y países "proletarios". Meissel Roca, Adolfo. "Prólogo" a Nieto Arteta, Luis Eduardo. Crítica a la economía política. Ensayos, Gonzalo Cataño compilador, Universidad Externado de Colombia, Bogotá, 2004, p. 11. 
No cabe duda que Nieto Arteta, en aquellos debates del Grupo Marxista (Cataño, 1983, pp. 191-192), ${ }^{83}$ profundizó en la intríngulis de las relaciones de producción capitalistas, a partir de un analítico estudio de la obra de Marx como lo demuestran sus reconocidos estudios económicos (Eastman, 1983, p. XI) ${ }^{84}$ especialmente sobre la historia económica colombiana (Meisel, 2004, p. 10$)^{85}$.

En el presente trabajo sólo se aspira a analizar algunos elementos de la evolución de las ideas del pensador barranquillero en relación con lo que generalmente se considera la filosofía marxista. Aunque algunos erróneamente consideren que este hecho fue una simple fiebre juvenil (Sierra, 1978, p. 118), y que por tanto sólo sus primeros trabajos (Sierra, 1978, pp. 153-154) ${ }^{86}$ estaban fundamentados en el marxismo (Eastman,

83 "Nieto encontró en el Grupo Marxista el medio más adecuado para desarrollar sus inquietudes intelectuales y su vocación de escritor. Allí discutió los más diversos temas relacionados con la teoría marxista, la política, los conflictos sociales, y al calor de estas disputas comenzó a interesarse por la historia nacional y los problemas económicos del país. A semejanza de sus colegas, tomó el marxismo como un instrumento de investigación para esclarecer las fuentes de la dinámica social y comprender el sentido que informaba el futuro de la humanidad." Cataño, Gonzalo. "Luis E. Nieto Arteta: Marxismo y participación política". El marxismo en Colombia, Universidad Nacional, Bogotá, 1983, pp. 191-192.

84 "Así Nieto Arteta desarrolla conceptualmente la categoría económica de la renta, apoyándose, en lo fundamental, en los escritos de Marx. Explica inteligiblemente que la renta se define como una sobretasa o tasa extraordinaria de ganancia, obtenida a partir de determinadas relaciones de cambio, afirmando, así mismo, que no es característica exclusiva de la tierra la de generar renta." Eastman, Jorge Mario. "Presentación". Nieto Arteta, Luis Eduardo. Obras selectas, Imprenta Nacional, Bogotá, 1983, p. XI.

85 En particular, su ensayo "El café en la sociedad colombiana", redactado en 1948 y publicado solo después de su muerte, es muy apreciado por los historiadores y científicos sociales contemporáneos" Meisel Roca, Adolfo. "Prólogo". Nieto Arteta, Luis Eduardo. Crítica a la economía política. Ensayos, Universidad Externado de Colombia, Bogotá. 2004. p. 10.

86 "Y justamente por haber puesto el acento de sus investigaciones en el aspecto económico se lo ha apreciado como a un pionero de la moderna historiografía nacional. Pero esa actitud economicista ha dado origen a un equívoco en nuestros medios intelectuales: se habla con algún apresuramiento de las interpretaciones marxistas del autor de Economía y cultura. El propio Nieto Arteta no fue ajeno a este equívoco. Sin embargo, ni en sus interpretaciones de la historia ni en sus análisis filosóficos adoptó la metodología marxista ni logró un manejo correcto de las categorías dialécticas cuando, en ocasiones, recurrió a ellas. Algunas indicaciones metodo- 
2000, p. 119), ${ }^{87}$ en verdad, de un modo u otro el marxismo, como método de análisis, quedaría marcando toda su obra posterior, especialmente sus estudios históricos, como Economía y cultura en la historia colombiana (Melo, 1968, p. 655) ${ }^{88}$ publicada en 1942, así como en otros análisis económicos y sociales posteriores a esa fecha, aunque no fuese así en el caso de sus ideas filosóficas. Resulta mucho más objetiva la conclusión de Gonzalo Cataño, según la cual "El marxismo animó su formación inicial y lo asistió los años siguientes, pero jamás fue una jaula de hierro que le impidiera el acercamiento a otras tradiciones de pensamiento. Era un marxismo abierto, sin fronteras, a pesar de que con frecuencia cayera en ortodoxias insufribles" (Cataño, 2013, p. 105).

lógicas consignadas en el prólogo de su obra, ponen en claro cuán lejos estaba del pensamiento historiográfico de Marx, como cuando interpreta el hecho histórico como una individualidad que se ha de comprender intuitivamente, y sobre todo cuando expresa que su deseo es aprehender la "significación intencional" de estos hechos. Si hemos de atenernos a ciertos rasgos de la terminología que adoptó en aquellas consideraciones metodológicas, podemos suponer que se proponía en Economía y cultura una especie de "fenomenología" de nuestra historia económica. No obstante nos ofrece otra cosa, en donde quizá debamos buscar sus méritos: una historia descriptiva de la economía colombiana, que por lo demás no logra superar la actitud positivista." Sierra Mejía, Rubén. Nota sobre la filosofía del derecho de Nieto Arteta, Ensayos filosóficos, Ed Andes, Bogotá, 1978, pp. 153-154.

87 "Sus numerosos escritos son elocuente testimonio la intensidad intelectual desarrollada durante sus escasos veinte años de vida activa. Sus primeros trabajos se alimentaron del marxismo como método de investigación social, del cual se nutrió en los años de estudiante universitario al calor de las discusiones teóricas y de las luchas estudiantiles que por la década de 1930 se encontraban en plena ebullición. Su pensamiento y su actitud frente a la política se definieron desde cuando cursaba su segundo año de derecho." Eastman, Jorge Mario. Trece pensadores del Liberalismo social, Dirección Liberar Nacional, Bogotá, 2000, p. 119.

88 "El autor ofrecía allí un ensayo de aplicación de una metodología constantemente definida de orientación marxista, a la investigación y comprensión de la historia colombiana del siglo xIx. No se trataba de un marxismo de corte ortodoxo, pero el interés de aplicar los sistemas de las superestructuras políticas y jurídicas y de las formas ideológicas (especialmente teorías políticas y económicas) a partir de la estructura económica, que constituía el principal interés teórico del libro, estaba a todas luces motivado por los elementos marxistas del pensamiento de Nieto Arteta". Melo Jorge Orlando. "La literatura histórica en la Republica" en Manual de literatura colombiana, Planeta, Bogotá, 1968, vol. II, p. 655. 
Del mismo modo que resulta bien fundamentado el criterio de Hernán Ortiz, quien afirma: " La obra de Nieto Arteta debe figurar como pionera de la aplicación del marxismo a la economía y cultura de nuestra historia, lo mismo que como teoría científica de la filosofía moderna" (Ortiz, 2008, p. 26).

Nieto Arteta, a mediados de los años cuarenta, consideraba que la filosofía marxista se había desarrollado en la Unión Soviética cuando afirmaba "Alemania es la patria y el hogar de la filosofía sea ella burguesa o proletaria. Actualmente, necesario es decláralo, los filósofos rusos han ampliado y desarrollado con hondos aciertos la concepción marxista del mundo" (Nieto, 1978b, p. 155). Este planteamiento no se alejaba de la verdad, pues ha sido muy común considerar unilateralmente con un enfoque nihilista que toda la producción filosófica rusa de la época de existencia de la Unión Soviética resulta inservible en el presente. Tal consideración resulta tan insustentable como la que era común en la perspectiva prevaleciente en el marxismo soviético según la cual toda la filosofía antigua, medieval, moderna y la "burguesa contemporánea” constituían un ensarte de errores. Tal concepción era en verdad muy distante tanto de los criterios de Marx que siempre admiró no solo a los filósofos griegos, sino que citó a Tomas de Aquino en su obra El Capital y se refirió muy elogiosamente a los nominalistas escolásticos, a los ilustrados, especialmente a Rousseu, así como a los pensadores clásicos alemanes especialmente a Kant y Hegel.

Engels sostenía que si todo lo que plantean los filósofos idealistas fuese falso, sería muy fácil criticarlos y en verdad ese no ha sido el caso. Por su parte, Lenin aconsejaba a su esposa Nadiezda Krupskaia que se reeditaran las obras de los filósofos de la Ilustración, a quienes consideraba honestos ideólogos burgueses, que resultaban muy valiosas por lo que se debían extraer de ellas sus núcleos racionales. Imbuidos de ese criterio metodológico es que nos hemos dedicado a rescatar las ideas humanistas contenidas en diversas épocas del pensamiento filosófico latinoamericano (Guadarrama, 2012a, 2012b, 2013).

Por otra parte, Nieto Arteta no veía al marxismo como algo desvinculado de toda la herencia filosófica, económica e ideológica que le había antecedido, como había destacado Lenin. A su juicio, con razón, el marxismo era 
un producto del racionalismo (Nieto, 1941, p. 394) ${ }^{89}$ y a la vez estaba orgánicamente articulado como una continuidad del liberalismo (Nieto, 1943, p. 263), ${ }^{90}$ lo mismo en el plano científico como por sus aspiraciones de lograr un mejoramiento de las condiciones de vida de los hombres.

De manera que se debe tener presente que no todo lo que se produjo en el terreno de la filosofía marxista tanto en la otrora Unión Soviética, ni en los países de Europa Oriental en el periodo que se suponía construían el socialismo, debe objetivamente, subestimarse o considerarse simples manuales de divulgación. Hubo numerosos pensadores que enriquecieron la filosofía marxista como el controvertido Lukács, así como Kedrov, Kopnin, Ilienko, Holz, Kosik, Schaff, Gedo, entre otros, cuyos aportes filosóficos resultan de valor, independientemente de la caída del socialismo en aquellos países.

Nieto Arteta equívocamente criticó algunas de las que consideraban eran las limitaciones deterministas o presuntamente naturalistas del marxismo, al punto de llegar a afirmar lo siguiente: "El materialismo histórico acentúa aún más la tendencia a la objetivación y la naturalización, pues identifica la sociedad y los hechos a ella unidos, con un conjunto de realidades materiales, exteriores al hombre. En la concepción materialista de la historia, la naturalización es plena y agotadora. Labriola así lo ha advertido" (Nieto, 1978b, p. 41). Pero esta perspectiva errónea de la articulación entre los fenómenos naturales y sociales según la concepción materialista

89 "El marxismo formado en el ambiente histórico creado por la filosofía racionalista, debía ineludiblemente distinguirse a pesar suyo, por una interpretación metafísica y racionalista de la realidad. El marxismo se formó en el regazo del racionalismo." Nieto Arteta, Luis Eduardo. "Virtualidad creadora de la dialéctica", Universidad de Antioquia, No. 48-49. Medellín, Agosto-septiembre, 1941, p. 394.

90 "Nadie, por lo demás, podrá negar La vinculación intelectual que existe entre el marxismo y el liberalismo. ¿No fue David Ricardo quien suministró, en un cierto sentido, la teoría del valor ampliada y aclarada por Marx? Haciendo el nacional-socialismo una crítica del significado racionalista del liberalismo y el marxismo, se presenta como una afirmación de la vida, de lo elemental y primario, de las fuerzas y tendencias vitales del hombre. La concepción nacional-socialista del mundo y de la vida es una afirmación de lo irracional. Ante la razón sostiene la vida, ante el esquema de la destrucción de toda categoría formal y lógica." Nieto Arteta, Luis Eduardo. Revista del Colegio de Abogados, Año XVIII, agosto-noviembre de 1943, No. 64-65, Medellín, p. 263. 
de la historia que se observa en sus primeros trabajos no solo se manifestará sino que se profundizará en la etapa final de su vida, al caracterizar el marxismo como un naturalismo, un realismo ingenuo y una especie de materialismo vulgar, que reduce toda la compleja vida social a un monismo naturalista, (Nieto, 1960, pp. 32-33) ${ }^{91}$ —algo alejado en verdad de las

91 "Este capítulo suministra una propicia ocasión para explicar la posición del autor (Engels) ante el marxismo y muy peculiarmente la dialéctica de la naturaleza, tal como la ha definido el marxismo. El atento lector habrá comprendido que para el autor la citada dialéctica es una objetiva aprehensión del contenido de la realidad natural. En otras palabras, que la ontología de lo natural es la dialéctica materialista sustentada por el marxismo. Pero éste incurrió, siguiendo una tendencia muy generalizada en la época en que se formó, en un erróneo monismo naturalista, identificando la realidad con la realidad material. Aquella época es acendradamente monista. El marxismo tenía que serlo también. La sociología positivista había naturalizado la realidad social. Para Augusto Comte y sus discípulos las leyes sociales eran idénticas a las naturales y la evolución de las sociedades análoga a la de las especies animales. Es una época de la cultura que sufre una tremenda expansión del naturalismo y del materialismo. Ya la misma filosofía kantiana había sido una exploración de las condiciones del conocimiento natural y del conocimiento matemático. No se había planteado todavía el problema de los supuestos del conocimiento de la realidad histórica. Ante el brevemente aclarado monismo naturalista del marxismo cabe afirmar un descubrimiento fenomenológico: las dialécticas regionales. Cada esfera de la realidad encierra sus propias contradicciones, sus peculiares antinomias. No hay una sola dialéctica, hay varias. En lugar del monismo dialéctico de Hegel y Marx debe sostenerse un pluralismo dialéctico. La fenomenología ha pluralizado la realidad. En la presente obra, como también habrá advertido ya el acucioso lector, hay una permanente vinculación entre la dialéctica y la fenomenología. El autor se ha visto conducido, así, a aceptar el descubrimiento de las contradicciones especiales de las distintas esferas de la realidad. Además, ha intentado, objetiva o inexactamente, ampliar el contenido de la dialéctica de la realidad natural. Por eso, ha querido mostrar que esa realidad es una totalidad. Es una afirmación que, obviamente, no se puede encontrar en los autores marxistas, ni aún en los contemporáneos.

La elucidación del problma de las lógicas regionales ha llevado al autor a una superación de la actitud marxista ante la lógica formal. Me remito a las observaciones hechas en páginas anteriores. Es posible descubrir una lógica formal dialéctica. Contrariamente a la oposición de los marxistas la lógica formal no es inevitablemente metafísica.

Hay otras teorías filosóficas marxistas que no están directamente relacionadas con la ontología de la naturaleza y que, por ende, no deben ser comentadas detenidamente en este capítulo. Una de ellas es la teoría de la praxis y del conocimiento. Hay en la gnoseología marxista una descripción del origen de los conocimientos, pero no una teoría dialéctica del conocimiento. El marxismo defiende un realismo ingenuo, es el eterno e insuperable realismo ingenuo". Nieto Arteta, 
concepciones ontológicas y epistemológicas del marxismo- lo que evidencia de que no manejó los fundamentales trabajos filosóficos de Marx y Engels como La ideología alemana, entre otros, e incluso cuando utiliza el término praxis, realmente está muy lejos de comprender en qué sentido Marx, en sus tesis sobre Feuerbach, destacó el valor del idealismo filosófico en el reconocimiento del papel del lado activo, es decir del sujeto en el proceso del conocimiento.

De la misma forma, parece que tampoco conoció las valiosas apreciaciones de Lenin en sus Cuadernos filosóficos respecto a la necesidad de justipreciar el valor de lo que caracterizó como idealismo inteligente, léase Aristóteles, Kant, Hegel, entre otros, por sus mayores aproximaciones al materialismo inteligente, es decir el de Marx y Engels que las que había tenido el materialismo vulgar o torpe, como el de la ideología, esto es, Destutt de Tracy, Cabanis, Vogt, Moleschott, y otros, que habían considerado a las ideas como una simple excreción material de la glándula cerebral.

En ese aspecto no llegó a distinguir adecuadamente entre Marx y algunos autonombrados marxistas, que con más o menos razón han conducido a algunos analistas de tales versiones del marxismo a emparentarlo con el positivismo (Herrera, 1982, p. 383). ${ }^{92}$ De manera que Nieto Arteta forma parte también de la oleada antipositivista — sui generis como el positivismo que le antecedió- que permeó la vida filosófica y cultural en general de

Luis Eduardo. Lógica y ontología, Ediciones del Cincuentenario del Atlántico, Barranquilla, 1960, pp. 32-33.

92 "La distinción entre ciencias de la naturaleza y ciencias de la cultura establecida por Ricker fue el punto de partida de su reflexión filosófica, al mismo tiempo que lo llevó a un distanciamiento del marxismo y a una permanente critica del positivismo. Tanto el uno como el otro pecan por su excesivo "naturalismo". Si bien es cierto que las ciencias de la naturaleza poseen un sentido totalmente objetivo, en las ciencias de la cultura el sentido depende de la existencia de un sujeto. De aquí la necesidad de elaborar las ontologías regionales correspondientes a los diversos modos de ser y una ontología pura que ponga al descubierto el contenido antinómico de las diversas esferas de la realidad. Para la elaboración de estas ontologías Nieto A. busca el apoyo de la fenomenología como ciencia eidética y descriptiva, pues considera que "el metafísico y sistemático 'método dialectico' - Hegel, Marx, Engels_-" no permite poner a descubierto lo típico de los modos de ser del hombre, de lo social y lo jurídico, modos que fueron los que más le interesaron". Herrera Restrepo, Daniel "La filosofía en la Colombia contemporánea (1930-1988), en Marquínez, Germán y otros, La filosofía en Colombia, p. 383. 
Latinoamérica durante la primera mitad del pasado siglo xx (Guadarrama, 2011, p. 134). ${ }^{93}$

Estas controvertidas posturas de Nieto Arteta ante el marxismo en diferentes planos, como ontológico y epistemológico, no deben considerarse como una total ruptura o distanciamiento en todos las cuestiones esenciales que aborda esta teoría, pues aún en sus trabajos finales se pueden observar innumerables puntos de coincidencia en diversos aspectos, incluso de carácter epistemológico, como cuando analiza la dialéctica correlación entre la verdad absoluta y la verdad relativa, en la que sin hacer referencia al Materialismo y empiriocriticismo de Lenin parece coincidir en lo fundamental con el pensador ruso al sostener:

Si a cada esfera de la realidad corresponden una categoría pura y unas determinadas y limitadas categorías fundamentales, habrá una verdad inmutable de aquéllas y de éstas, no sin olvidar, sin embargo, que la verdad que se da en la historia de la cultura es una unidad y división de la verdad absoluta y la verdad relativa. No hay una verdad absolutamente invariable. Hay, sí, una verdad que aun siendo una adecuación entre la realidad y el pensamiento, supone una transformación incesante en el sentido de una aprensión constantemente más objetiva de la realidad. (Nieto, 1960, pp. 14-15).

93 "A partir de inicios del siglo xx, la oleada antipositivista sui géneris que sacudió la vida intelectual de América Latina se caracterizó por tratar de reivindicar el idealismo y el vitalismo espiritualista frente a lo que comúnmente constituía la vulgarización del materialismo y el biologicismo. Fue sui géneris esta reacción contra el positivismo, en primer lugar porque se generó entre intelectuales jóvenes que en su mayoría habían compartido inicialmente la tesis de aquel positivismo sui géneris, el cual por muchos elementos comunes que tuvo con el europeo, también se había distanciado sustancialmente de él. Esta nueva generación encontró no solo en nuevas tendencias de la filosofía de orientación vitalista, irracionalista, voluntarista y fideista, como apreciaron en Nietzsche, Bergson, Ortega y Gasset, etc., sino en algunos pensadores latinoamericanos como José Martí que les sugería reflexionar sobre el "hombre natural" y las circunstancias históricas específicas de Nuestra América, en momentos tan peligrosos para conservar su integridad e identidad, cuando ya el intervencionismo yanqui había dejado ser una simple amenaza y lamentablemente se había convertido en un hecho". Guadarrama, Pablo. "Razones del positivismo y el antipositivismo sui géneris en América Latina". Cuadernos americanos. Universidad Nacional Autónoma de México. México. D.F. 2011. Año xxv. Vol. 3, n 137. p. 134. Disponible en: http://www.cialc.unam.mx/cuadamer/textos/ca137-125.pdf 
En el plano ideológico, sus ideas socialistas iniciales revelaban una confianza -incluso en los momentos más difíciles para la entonces Unión Soviética bajo la agresión nazi (Nieto, 2004, p.163) ${ }^{94}$ - en el triunfo de una sociedad más humana que superara al capitalismo que sólo producía mercancías (Nieto, 2004, p.17) ${ }^{95}$ Estas se irían apagando paulatinamente en los últimos años de su vida, tal vez más por coyunturas políticas que por determinaciones ideológicas, pero a mediados de los años cuarenta parece que aún confía en las posibilidades emancipadoras del socialismo, como puede apreciarse en sus reflexiones de 1945 sobre el posible uso de la energía atómica en las que plantea que :

La utilización industrial de la energía atómica, liberando una extraordinaria cantidad de trabajo humano, ofrece los supuestos necesarios para la creación de una ulterior economía socialista, cuyas condiciones serían suministradas por las mismas fuerzas productivas, tales como ellas se han desarrollado ya en el seno del vigente sistema capitalista. Liberándose esa gran cantidad de trabajo humano, es decir,

94 En 1943 planteaba: "Si terminada la guerra el mundo se organizase dentro de algunos espacios vitales continentales, hipótesis de difícil realización, o, por lo menos, el comercio internacional se regulase en determinado sentido, habríamos cumplido una nueva jornada en el inevitable tránsito de la economía capitalista a una futura economía socialista. Todo ello condicionado por el supuesto de que las potencias totalitarias sean vencidas. Lo cual no indica que sea imposible la formación de aisladas economías socialistas nacionales. Tal vez el presente conflicto permita en Europa la constitución de nuevas economías socialistas apoyadas en la economía de la Unión Soviética. Toda guerra forzosamente ha de contribuir a la formación de nuevas y distintas economías socialistas, porque crea condiciones adecuadas para la revolución". Nieto Arteta, Luis Eduardo. Crítica a la economía política. Ensayos, Gonzalo Cataño compilador, Universidad Externado de Colombia, Bogotá, 2004, p. 164.

95 En 1939 escribía: "La teoría marxista distingue el trabajo creador de valores de uso y el trabajo creador de valores de cambio. El primero es independiente de todo modo de producción, es decir, no sufre variaciones históricas. Siempre ha existido. En una economía socialista el trabajo producirá valores de uso. Por eso, una economía de esa índole puede definirse como una economía productora de objetos útiles pero no de mercancías. Por el contrario, el trabajo creador de valores de cambio sí está íntimamente unido al modo de producción existente en determinada jornada de la evolución histórica." Nieto Arteta, Luis Eduardo. Critica a la economía política. Ensayos, Gonzalo Cataño compilador, Universidad Externado de Colombia, Bogotá, 2004, p. 17. 
no siendo ella necesaria para la producción de mercancías (en una economía socialista no hay producción de mercancías sino fabricación de objetos útiles), los hombres tendrían mayores oportunidades para la plena realización de todas las posibilidades implícitas en cada vida individual (Nieto, 1978a, p. 56).

En ese artículo, en el que se observa al menos un conocimiento de las ideas de Engels - al menos de sus obras publicadas hasta ese momento- elaborado en la época de la derrota del fascismo por el decisivo protagonismo del pueblo soviético y de expansión del socialismo a Europa Oriental se revela su profundo optimismo en el socialismo cuando expresa, "No está remota la época en que el hombre se podrá realizar con plenitud. El eterno humanismo, en este caso un humanismo proletario, hará alegre y dichosa la vida humana. La sociedad socialista y la economía socialista serán el ambiente, el medio en los cuales se realizarán ese humanismo y esa alegría existencial" (Nieto, 1978a, p. 59).

Debe destacarse que su concepción al respecto se opuso a todo tipo de reproducción mimética del socialismo y mucho menos a la común postura de los partidos comunistas subordinada por entonces a la orientación stalinista, durante la época que le correspondió vivir. En ese sentido, su perspectiva inicial respecto al socialismo se identificaba más con las ideas de su coterráneo Antonio García Nosa e incluso con las de José Carlos Mariátegui (Guadarrama, 1995, pp.109-117), si bien estos, hasta el final de sus días, no se avergonzaron de sus posturas ideológicas al respecto, como no fue el caso de Nieto Arteta. Al propugnar modalidades propias de los países latinoamericanos en la posible construcción de sociedades de orientación socialista, este último adoptaba una postura mucho más consecuente y por lo tanto auténtica, que los partidos comunistas, en cuanto a la articulación de pensamiento latinoamericano con el universal (Cataño, 1983, p. 173). ${ }^{96}$

Desde sus primeros escritos se destaca claramente en el pensador colombiano no solo un manejo de algunas de las ideas de Marx en el plano fi-

96 “(...) afirmó que si bien el socialismo era universal, no por ello se podía olvidar que cada nación le imprimía características específicas. Era por tanto legítimo, hablar de un socialismo colombiano como de uno español". Cataño, Gonzalo. "Luis Eduardo Nieto Arteta: marxismo y participación política" en Colectivo de Autores. El marxismo en Colombia. Universidad Nacional. Bogotá. 1983. p. 173. 
losófico, por lo que no se le debe considerar un simple marxólogo, sino que también se observa su identificación con su proyección ideológica, pero ante todo su alta estimación epistemológica, por lo que no vacila en sostener, "El marxismo me ha enseñado a ser realista, a buscar lo que existe, no lo que según nosotros debe existir" (Eastman, 1983, p. VIII). ${ }^{97}$

Algo que desde muy temprano valoró en el marxismo, si bien con algunas confusiones e imprecisiones fue la dialéctica. A su juicio, "El método dialéctico de Carlos Marx demuestra cómo el capitalismo crea las condiciones objetivas que hacen inminente su desaparición. Las tendencias inmanentes de 'las fuerzas de producción', destruyen las 'relaciones de producción' determinadas en una cierta etapa histórica del capitalismo. Hay que advertir que 'las relaciones de producción' no desaparecen, mientras en su seno 'las fuerzas de producción’ no hayan alcanzado el desarrollo que ellas les permitan, sin destruirse a sí mismas" (Nieto, 1978, p. 19).

Pero algunas de sus tempranas visiones de la dialéctica evidentemente están permeadas por la interpretación que de las concepciones engelsiana de la misma y en su perspectiva epistemológica las que habían realizado de las interpretaciones del marxismo soviético predominante en esa época (Nieto, 1939, p. 716). ${ }^{98}$ Este hecho se observa cuando considera que:

La dialéctica [...], es, o pretende ser, una forma de la inteligibilidad de la materia. Hay en el mundo un conjunto de procesos interminables,

97 "Política socialista colombiana”, artículo publicado en Revista Jurídica, números 225-226 (Bogotá), agosto-septiembre de 1932. Vale la pena anotar que cuando Nieto Arteta escribió este artículo contaba con diecinueve años de edad, siendo ya miembro de la Sociedad Jurídica, asociación profesional de los estudiantes de la Escuela de Derecho de la Universidad Nacional, para cuyo ingreso era necesario presentar un ensayo de buena calidad intelectual". Eastman Jorge Mario. "Presentación (1979)," en Nieto Arteta. Luis Eduardo. Obras selectas, Imprenta Nacional, Bogotá, 1983, p. VIII.

98 “Además, el formalismo tan sólo obtiene una total realización teórica, o puede obtenerla, en la teoría del conocimiento. La epistemología debe orientarse en un sentido formalista. Especialmente la epistemología dialéctica. La dialéctica puede definirse 'la forma de la inteligibilidad' de la materia. Es por eso, la comprensión dialéctica del mundo, una estructura o elaboración gnoseológica de formas vacías dentro de las cuales se coloca la contradictoria y fluctuante realidad." Nieto Arteta, Luis Eduardo. Derecho, Revista del Colegio de Abogados, Medellín, año XIII, Tomo V noviembre de 1939, número 49, p. 716. 
de transformaciones permanentes, de movimientos constates. No hay reposo, no hay inmovilidad. Ahora bien, el movimiento es suscitado por los estados contradictorios, por las oposiciones que vive toda cosa, todo objeto. Las contradicciones ocasionan el proceso de transformación que viven todos los objetos. Si ellas desaparecieren, las modificaciones de la realidad serían incomprensibles. Ya, como observa Engels, el movimiento es una pura contradicción y solamente es comprensible por las contradicciones. De las anteriores observaciones fluye una definición de la dialéctica. Es la 'ciencia de las leyes generales del movimiento'. Es el estudio de las transformaciones incesantes que sufren las cosas y de las leyes que informan tales transformaciones. La dialéctica rechaza el sistema. Se intentará demostrar que el marxismo es, sin embargo, un sistema. Para comprender esta crítica dialéctica del marxismo, será necesario esbozar antes una teoría del sentido de las contradicciones que desgarran a toda realidad (Nieto, 1978b, p. 32).

Con anterioridad ya había expresado su crítico distanciamiento de las interpretaciones simplificadoras de la dialéctica — que los manuales soviéticos de marxismo-leninismo habían propagado y que el propio Engels había propiciado-, cuando en carta a un amigo planteaba:

Dentro del método que he utilizado en el estudio histórico de que te he hablado en párrafos anteriores, lo que podría considerarse como la tesis dentro del rígido método dialéctico del materialismo histórico, es un momento múltiple y diverso, multilateral, el cual encierra ya muy tremendas contradicciones. Por otra parte, he rechazado la teoría de que las contradicciones de la tesis y de la antitesis sean destruidas dentro de la síntesis, [es decir, que] sean eliminadas en una entidad superior. Bajo este aspecto, por consiguiente, también he abandonado el materialismo histórico. En realidad de verdad, la eliminación de las contradicciones de la tesis y de la antítesis en una realidad superior y armónica, sería el estancamiento, la inmovilidad." (Cataño, 2013, p.183).

Si Marx intentó en vano explicarle a Proudhon la esencial diferencia entre su concepción de la dialéctica y la de Hegel, parece que tampoco Nieto Arteta la entendió, como puede apreciarse en su controvertido intento de comparar las divergentes perspectivas que de la dialéctica tenían aquellos dos primeros pensadores y considerar que quien poseía un verdadero pensamiento 
dialéctico era el anarquista francés y no Marx (Nieto, 1940, p.303), ${ }^{99}$ afirmación esta que puede sorprender no solo a un marxista, sino a cualquier estudioso del tema independientemente de su afinidad ideológica (Bermúdez, 1998, pp.14-15). ${ }^{100}$

Por supuesto que la concepción materialista de la historia constituye un enfoque sistémico no solo del desarrollo social, sino de la adecuada imbricación entre este y la naturaleza, superador de los maniqueos enfoques dicotómicos prevalecientes hasta esa época y que aún en la actualidad sobreviven. La holística concepción marxista de la dialéctica entre la naturaleza y la sociedad basada en su concepción monista materialista, sin duda encerraba una visión sistémica del mundo. Pero otra cuestión es que se trate de reducir el marxismo a una especie de sistema metafísico cerrado que precisamente fue criticado tanto por Marx como por Engels para diferenciase de todos los andamiajes especulativos que hasta su época se habían erigido de la realidad, como era el caso del sistema de Hegel (Nieto, 1978 b, p. 47). ${ }^{101}$

99 "Plejanov escribió (...) 'En esta discusión la victoria de Marx fue la de un hombre que sabía pen ᄀsar dialécticamente, pero que se había esforzado, no obstante, por aplicar el método dialéctico al análisis de la sociedad capitalista'. Yo estimo, contrariamente, que la polémica Marx-Proudhon fue el triunfo de un hombre que sí pensaba dialécticamente, - Proudhon- sobre otro que no pensaba dialécticamente pero que creía que pensaba dialécticamente, - Marx-." Nieto Arteta, Luis Eduardo. Posibilidad teórica de un marxismo spengleriano, Universidad de Antioquia, No. 42, Medellín, septiembre-octubre de 1940, p. 303

100 "Dotado de una inteligencia superior para el manejo de las categorías abstractas y de un donaire incomparable para plasmar el pensamiento en la palabra escrita, Nieto no tuvo en cambio la visión histórica correcta para escoger los autores y pensadores que pudieron adoquinarle el camino del conocimiento hacia horizontes verdaderamente comprometidos con el porvenir. Interesado en superar la dialéctica de Marx, por ejemplo, no lo hace disolviendo las vetustas categorías hegelianas en un nuevo molde de pensamiento, como el de Schlick o el de Avenarius, el de Mach o el de Wittgenstein, pensadores con preocupaciones epistemológicas endosadas al destino de la ciencia o encaminadas a dilucidar filosóficamente las posibilidades del lenguaje, sino que se empantana inexplicablemente con la obra de Proudhon, filósofo de poca monta, verificando glosas abstrusas y recomponiendo spenglerianamente galimatías dialécticas de pobre perfil gnoseológico y corto vuelo metafísico." Bermúdez Barrera, Eduardo. La dialéctica en Luis Eduardo Nieto Arteta, Ed. Centro Russell, Barranquilla, 1998, pp. 14-15.

101 "La dialéctica hegeliana y la dialéctica marxista son metafísicas y sistemáticas. He ahí su gran tragedia intelectual, su indecible sino y su desgarradora contradicción dialéctica. En la dialéctica marxista también debían realizarse las contradicciones 
Su incomprensión de la sustancial diferencia cualitativa del método dialéctico de Hegel y de Marx parte de una incorrecta deducción según la cual:

La dialéctica marxista, esto también es muy sabido, es la misma dialéctica hegeliana modificada radicalmente en su sentido real, es decir, en el contenido de la realidad que varía a través de contradicciones. En Hegel esa realidad era la Idea; en Marx es la materia misma. En el prólogo de la segunda edición de 'El Capital' escribió Carlos Marx: 'Mi método dialéctico se diferencia del de Hegel no sólo por tener base distinta, sino por ser su antítesis directa. Para Hegel es el proceso dialéctico al que bajo el nombre mismo de Idea transforma en sujeto substancial el demiurgo de lo real, siendo la realidad sólo su forma de manifestación externa. Para mí, por el contrario, lo ideal no es más que la transmutación y traducción que sufre lo material al pasar por el cerebro humano' (Nieto, 1942, pp. 236-237).

Tal vez una lectura literal de esta última oración haya llevado al pensador colombiano a, en lugar de comprender la determinación marxista de la conciencia social por el ser social, una simple ecuación de materia vs idea.

Para Marx el ser social incluía no solo los indispensables componentes materiales que exige el modo de producción, es decir, las fuerzas productivas y las relaciones de producción, sino también el medio geográfico y la población. Por supuesto que estos sustanciales elementos no existían en una frígida rigidez material descontaminada de todo elemento ideal en el proceso de trabajo, producción, intercambio y consumo, así como a través de las interacciones ideológicas plasmadas en las instituciones jurídicas y políticas. Por el contrario, todo un conjunto de mediaciones ideales y conscientes hacen que el ser humano trabaje, pueda crear valores y apropiárselos. De otro modo habría que admitir la existencia de un metafísico muro

que ella descubrió en la realidad. Y su mayor contradicción es esa conservación ilógica, extraña, incomprensible de la metafísica y del sistema. Rechazada la concepción dialéctica del marxismo, y habiendo intentado demostrar que en ella se conserva todavía la metafísica y se afirma el sistema, es necesario estructurar una nueva filosofía dialéctica, auténtica y decididamente dialéctica, desligada de todo impuro contacto con la metafísica y con una comprensión sistemática del mundo y de la vida." Nieto Arteta. Luis Eduardo. "Dos dialécticas: Marx y Proudhon (1941)," en Ensayos históricos y sociológicos, Instituto Colombiano de Cultura, Bogotá, 1978, p. 47. 
divisor entre lo material y lo ideal, que por supuesto para Marx y Engels no existía porque la praxis humana lo mediaba con creces. Tal confusión se observa cuando se analizan estas reflexiones del pensador colombiano:

Engels, por lo demás, lo declara repetidamente y de manera tal que no puedan surgir dudas: "Marx y yo hemos transportado la conciencia de la dialéctica de la filosofía idealista alemana a la concepción materialista de la naturaleza y de la historia". Más surge un nuevo problema: ¿cuál es el contenido de la forma de la inteligibilidad de la materia, de la realidad? $\mathrm{O}_{¿}$ Cuál es el sentido de las contradicciones de la realidad, contenido de esa forma de la inteligibilidad de la materia? He aquí el momento en el cual se separan la dialéctica marxista y la dialéctica o concepción dialéctica del mundo cuya definición se explicará en los párrafos siguientes. Para la dialéctica materialista del marxismo, el sentido de las contradicciones que desgarran a toda realidad, es el indicado por el tránsito de un primer momento - tesis-, aun segundo momento - antítesisy la eliminación o superación de las oposiciones que median entre esos dos momentos, en uno tercero, denominado síntesis. Es la muy conocida triada hegeliana. (...), entre esos tres momentos hay una oposición mecánica, espacial, que hace del proceso de las contradicciones de la realidad, una distinción artificiosamente establecida entre tres momentos que se separan mecánicamente. En ello reside la quiebra de la dialéctica en el seno de la concepción marxista de la misma. Es decir, el marxismo, la filosofía dialéctica por él definida, no son adecuadamente, auténticamente dialécticos. Hay un desgonzamiento, una extinción de la dialéctica. Tal es el sino intelectual del marxismo: no ser irrevocablemente dialéctico. (Nieto, 1978b, p.35).

Esta última conclusión, en caso de fuese aceptable, diferenciaría de manera novedosa a Nieto Arteta sustancialmente en cuanto a la relación de la dialéctica con el marxismo no solo de los identificados con esta filosofía, sino también hasta de sus más claros críticos o enemigos. Pero son varios autores 
los que consideran algo controvertida su postura respecto a la dialéctica, en particular ${ }^{102}$ y el marxismo en general.

Ahora bien, llama poderosamente la atención una lectura de la obra de Nieto Arteta en perspectiva evolutiva desde sus escritos de juventud hasta su madurez pues; por una parte, prevalece un enfoque filosófico marxista tanto en el plano epistemológico y metodológico e incluso ideológico, por lo menos en este último aspecto hasta mediados de los años cuarenta; y a la vez, trata de comparar e incluso articular eclécticamente el pensamiento de Marx con autores de una talla intelectual generalmente considerada como inferior como Proudhon o Spengler (Cataño, 2013, p. 188). ${ }^{103}$ En relación a este último su admiración por él fue tan grande que le condujo a sostener algunas afirmaciones sin ninguna base de sustentación como la siguiente: "Ya conocemos las críticas spenglerianas a la teoría de la causalidad. Pues bien, la dialéctica materialista del marxismo rechaza igualmente la noción o la interpretación causalista de la realidad física y social" (Nieto, 1940, p. 304) y por tal razón considera que la dialéctica marxista es una especie de teleología (Nieto, 1934, p.42). ${ }^{104}$ No es menos cierto que en determinadas

102 Así en 1941 inicia una "critica dialéctica" del marxismo en su ensayo "Dos dialécticas: Marx y Proudhon." Esta críticas no están extensas de inconsistencias y contradicciones en la que se aprecia su esfuerzo para construir un método de análisis de la realidad social." Gómez Martínez, Alberto. Nieto Arteta y la nueva lectura de la historia de Colombia, Magazín Del Caribe. No 9 Bogotá, junio, 2007, p. 12.

103 "Estas aproximaciones de enfoques antagónicos no llevaron a Nieto a rechazar el marxismo. En realidad pretendía enriquecerlo. Sabía que el legado de Marx era una 'adquisición irrevocable'. Mientras que el materialismo primitivo se limitaba al examen de la naturaleza, el materialismo histórico lo ennoblecía con un campo adicional: el estudio de la sociedad." Cataño, Gonzalo. La introducción del pensamiento moderno en Colombia. El caso de Luis E. Nieto Arteta, Universidad Externado de Colombia, Bogotá, 2013, p. 188.

104 "También en el descubrimiento de fines en el hombre social, es un aspecto de la cultura moderna, a la cual hay que considerar como el conjunto de las expresiones psíquicas de la fuerza expansiva de la técnica moderna, como se ha repetido varias veces en estas páginas. Donde aparece con más claridad la existencia de fines sociales, es en el seno de la concepción materialista de la historia. En efecto, dicha concepción demuestra que aun cuando el capitalismo es autodestructor, pues él mismo crea las condiciones objetivas que lo harán innecesario, debe haber una clase social, que sola o unida a otras, haga posible su desaparición. Convierte, pues, un conocimiento causal, científicamente discernido, en móvil voluntarista y teleológico de nuestras acciones, como hombres pertenecientes a determinadas 
interpretaciones dogmáticas y simplificadoras del marxismo han aparecido concepciones teleológicas, especialmente en cuanto a las posibilidades del triunfo de revoluciones de carácter socialista en el mundo. Sin embargo, se debe acudir a La ideología alemana para rescatar la visión marxiano-engelsiana del comunismo como movimiento crítico y superador del estado de cosas imperante en la sociedad capitalista

En verdad si fuesen acertadas todas esas controvertidas afirmaciones del pensador colombiano en relación con el marxismo y en particular de su concepción de la dialéctica habría que preocuparse seriamente por todos aquellos que en distintas generaciones intelectuales, con independencia de su filiación ideológica, han sostenido todo lo contrario a lo planteado por Nieto Arteta en relación a Marx, el marxismo y su método dialéctico.

A Marx y al marxismo se le ha querido, en múltiples ocasiones, vincular con las más contraproducentes concepciones filosóficas, teorías políticas, económicas, sociológicos, entre otras, pero no ha sido nota común que se le haya tratado de enlazar con la filosofía de la historia de Spengler (Nieto, 1940, p. 308), ${ }^{105}$ que no hay duda pudo levantar alguna admiración entre determinados sectores intelectuales en cuanto a la crisis de la cultura occidental, pero en modo alguno lo logró en significativos sectores políticos que luchaban contra la permanencia del capitalismo, como sí lo fue en el caso del marxismo.

Nieto Arteta al adentrarse en el estudio de la fenomenología y en particular en temas axiológicos, que con razón no había encontrado en la literatura marxista de la época, no pudo del todo desembarazarse de una perspectiva dialéctica del mundo en su pretensión de construir ontologías regionales

clases sociales. Que en el seno de la dialéctica histórico-materialista del marxismo, exista la teleología es incuestionable." Nieto Arteta, Luis Eduardo. Revista Jurídica, Editorial Renacimiento, No. 234, Bogotá, 1934, junio-julio, p. 42.

105 "Aun cuando la dialéctica sea la teoría filosófica de las leyes que regulan el movimiento de la materia o de la realidad, es también la forma de la inteligibilidad de lo real. Podría afirmarse que la dialéctica relativiza, armoniza el dualismo "forma-ley". Al respecto, parece colocarse más allá de la oposición "fisiognómica-sistemática”.Sin embargo, no se destruye con esa afirmación la analogía que une a la dialéctica con la fisiognómica en la extinción de las leyes rígidas en el plano del conocer." Nieto Arteta, Luis Eduardo. Posibilidad teórica de un marxismo spengleriano, Universidad de Antioquia, No. 42, Medellín, septiembre-octubre de 1940, p. 308. 
imbricadas orgánicamente a una totalidad de mayor nivel de generalidad en una ontología de lo social (Nieto, 1985, p. 132). ${ }^{106}$

El tránsito a una perspectiva fenomenológica - en el que paradójicamente por un lado filosóficamente declara abandonar el método dialéctico (G.P.A, entrevista. P.V) ${ }^{107}$ mientras en el plano de sus investigaciones

106 "La sociología ha de descubrir en cada época histórica la totalidad cultural que en ella se haya realizado y la concepción del mundo que informe a esa época. La ontología de lo social se limita a mostrar que toda Weltanschauung arraiga en un determinado valor fundamental y que éste es el supuesto de la coherencia y unidad que vincula entre sí a las expresiones todas de la correspondiente concepción del mundo y de la existencia. La sociología como ciencia de hechos ha de estar vinculada a una ontología regional y ésta es la ontología de lo social. Tal es el muy rico contenido de la ontología de lo social. Es ella una dialéctica de lo social. Descubre fenomenológicamente la unidad y división del ser y el deber ser en la realidad social. Describe la tensión recíproca y funcional de medios y fines en los hechos sociales. Analiza la significación trascendente, porque apunta al valor fundamental, de cada una de las expresiones en las cuales se realiza la concepción del mundo y de la vida. Descubre la totalidad cultural, vivencia de ese valor fundamental. Hay para ella una peculiar conexión de sentido en cada una y en todas las mencionadas expresiones. Es la coherencia, la unidad de sentido, la superación cualitativa de las significaciones parciales e individuales de cada una de las creaciones culturales en que se realiza la visión del mundo y de la existencia. Es la trascendencia, es la totalidad. Por eso, como reiteradamente se ha afirmado, la ontología de lo social es una dialéctica regional de la realidad social. Es una de las varias dialécticas regionales. Su objeto último es la sociedad. No corresponde a la ontología de lo social calificar valorativamente la realidad social dada. Su misión es más sencilla, más humilde: un descubrimiento y una descripción del contenido de los hechos sociales. Se pregunta qué es la realidad social, pero no se plantea el falso problema de cómo deba ser esa realidad, de cuál deba ser el contenido contingente y variable de la realidad social que se dé en determinado momento o haya de darse en ese momento. La ontología de lo social no es una política de lo social, ni podría serlo." Nieto Arteta. Luis Eduardo. "Ontología de lo social (1953)," en Ensayos históricos y sociológicos, Instituto Colombiano de Cultura, Bogotá, 1978, p. 132.

107 —Cuál es el sistema filosófico que usted considera más completo cuál el autor que usted más admira?

- Creo necesario decirlo que establecería una distinción entre el método y el sistema. Antes de Husserl todos los autores anteriores, que desde la remota Grecia hasta los neokantistas, sin excluir a Hegel Marx y Engels, han creado sus propios sistemas. El mismo llamado "método dialéctico" tiene un contenido sistemático, pues afirma apriorísticamente que descubrirá las contradicciones que encierra la realidad, antes de saber si realmente toda realidad es antinómica. Todos los sistemas son perfectos, porque el entendimiento humano dedicado a la tarea de construir, siempre hace obras perfectas. Considero que deben rechazarse todos los sistemas y aplicar el método fenomenológico que nos permite descubrir sin propósitos sistemáticos el con- 
sociales lo continúa utilizando- de la búsqueda de una dialéctica pura se observa desde mediados de los años cuarenta (Nieto, 1946, pp. 104-105) 108 $^{108}$ y de manera diáfana en su ponencia al I Congreso Nacional de Filosofía efectuado en 1949 en Mendoza, Argentina (Actas del Primer Congreso

tenido de la realidad. Así, la dialéctica sería una concepción de la vida y del mundo fenomenológicamente descubierta. Justamente, creo que se debe rechazar el denominado "método dialéctico" y aceptar el método fenomenológico. Tan sólo Husserl ha sido fiel al rechazo del sistema".G.P.A. "Habla el profesor Luis Eduardo Nieto Arteta. El actual pensum para filosofía debe modificarse por anacrónico”. Entrevista. p. V.

108 "La vida tiene peculiares modos de existir. Toda realidad ofrece y presenta al análisis, determinados modos de ser. La vida en cuanto realidad, realidad realísima, no podría ser una excepción. Además, en los modos de existir de la respectiva realidad se des-cubren objetivamente las antinomias que ella encierra. Hay en cualquiera realidad una unidad y división de los contrarios, unidad y división que se expresa justamente en aquellos modos. Ante esa unidad y división, y en lo que respecta al método, debe adoptarse una muy concreta actitud. En efecto, sería una posición sistemática, y por ende muy inexacta, afirmar que se aplicará un método que nos permita descubrir la contradicción de la realidad. El filósofo ignora si la realidad encierra antinomias. Tan sólo, y una vez que las haya descubierto, podría sostener que la realidad es evidentemente contradictoria. En tal virtud, sería un error declarar, antes de saber si la realidad tiene antinomias, que descubriremos a éstas. Debería repudiarse ese presunto método dialéctico cuya finalidad, tal como ella ha sido definida, sería la del descubrimiento de las contradicciones que alberga la realidad. No sabemos si la realidad tiene antinomias. Hay en esa finalidad del llamado método dialéctico un contenido sistemático. El sistema es la previa construcción apriorística y racional de la realidad. Hay, no una aplicación del mencionado método, sino un descubrimiento fenomenológico de las contradicciones de la realidad. Así la dialéctica, es decir, la concepción del mundo y de la vida que, una vez descubiertas las antinomias, afirma que toda realidad es una unidad y división de los contrarios, sería una concepción del mundo y de la vida descubierta fenomenológicamente. La ontología pura es una teoría pura de la unidad y división de los contrarios, unidad y división fenomenológicamente descubierta. Esa ontología es una dialéctica pura. También la dialéctica pura es una teoría de la trascendencia y de la unidad y división de la inmanencia y la trascendencia, una teoría de la totalidad pura y una teoría de la categoría pura. Está fuera de lugar explicar ese múltiple contenido de la dialéctica pura. Hay, además, unas ontologías o dialécticas regionales que analizan las contradicciones de las diversas esferas de la realidad. La filosofía de la vida es una ontología regional de la vida, ontología que nos entrega una descripción pulcra de las antinomias que encierra la vida. Tales contradicciones se expresan en los modos de ser de la vida, los cuales encierran una unidad y división de los contrarios." Nieto Arteta, Luis Eduardo. "Guillermo Dilthey". Universidad Nacional de Colombia. No. 6. Bogotá. abril, mayo, junio 1946. pp. 104-105. 
Nacional de Filosofía, 1950, p. 1179) ${ }^{109}$ que posteriormente le hace distinguir entre una "dialéctica pura" y una "dialéctica de la razón" (Nieto,1957), que en definitiva hace coincidir de algún modo con la lógica dialéctica. Pero aun así, la perspectiva marxista de la visión dialéctica subyacería y afloraría en múltiples ocasiones en sus investigaciones de carácter histórico, económico y social, aun cuando en el plano filosófico se hubiese distanciado de ella dadas sus aproximaciones a la fenomenología.

Era marcada su añoranza por que la filosofía alcanzara una mejor determinación y aprehensión de las esencias (Mantilla, 1956, p. 494) ${ }^{110}$ y parecía que, a su juicio, las encontraría mucho mejor en la fenomenología que en el marxismo. La ilusión de las posibilidades de la intuición eidética le sedujeron más que el ascenso de lo abstracto a lo concreto.

Pero en su conflictiva perspectiva no lograría nunca desembarazarse del enfoque que la concepción materialista de la historia le había proporcionado desde sus años mozos, de manera que sus incursiones filosóficas por el árido terreno de las esencias puras en la que daba riendas sueltas a su reconocida brillante inteligencia (Molina, 1987, p. 275), ${ }^{111}$ parecían aterrizar

109 "Sin la totalidad la realidad no sería indefinidamente variable. No habría dinamicidad creadora. La totalidad es, en tal virtud, la coexistencia de la unidad y la pluralidad, la unicidad y la multiplicidad. Se da en ella una peculiar unidad y división de contrarios. Toda realidad encierra antinomias. La tensión recíproca y funcional, las conexiones, las relaciones y la función son una expresión de las contradicciones que se pueden descubrir en la realidad. La ontología pura es, por eso, una dialéctica pura”. Nieto Arteta, Luis Eduardo. "Lógica, ontología y gnoseología." Actas del Primer Congreso Nacional de Filosofía (Mendoza 1949), Universidad Nacional de Cuyo, Buenos Aires 1950, tomo II, p. 1179. Disponible en: ///C:/Users/Pablo/ Documents/ponencia\%20Nieto\%20Arteta\%201949.pdf

110 "En un reportaje de 1946 -de hace diez años justamente- declaraba lo siguiente: "Concibo la filosofía como un descubrimiento y descripción de las esencias". Iluminado para siempre por la visión de esencias, ya no podría ser en este mundo fenomenal otra cosa que un extraño..." Mantilla Pineda, B. "La muerte absurda de Luis Eduardo Nieto Arteta”, Revista Universidad de Antioquia. No. 126, Medellín, julio-agosto-septiembre, 1956, p. 494.

111 "La figura señera del Grupo Marxista fue Nieto Arteta. A más de su resplandeciente inteligencia, tenía un don de asimilación que sus amigos y compañeros envidiábamos. Toda lectura que hacía, y él sabía seleccionarlas, lo enriquecía. Por eso, a edad temprana, tuvo una versación que se imponía al respeto: fue así como profundizó las relaciones entre el Derecho y la Filosofía, y de allí pasó al estudio de las Ciencias Económicas y de la Sociología. Eso lo habilitó para ser lo que fue: el ideólogo de su 
sobre la cruda realidad de las situaciones socioeconómicas y culturales de los pueblos latinoamericanos a quienes, desde una perspectiva también humanista y desalienadora, trataría de colaborar en su emancipación con optimismo fundamentado. En eso parecía coincidir con Gramsci en cuanto a pesimismo de la realidad y optimismo de la voluntad, aun cuando parece que no conoció la obra del marxista italiano o al menos no la referencia. Esto se observa en su lamentable análisis del hombre (Nieto, 1948, p. 223) ${ }^{112}$ y la cultura latinoamericana en el que parecía no encontrar nada de valor hasta

generación”. Molina, Gerardo. Las ideas socialistas en Colombia, Tercer Mundo, Bogotá, 1987, p. 275.

112 "El hombre latinoamericano es subjetivo, predominantemente subjetivo. La subjetividad es su acento primordial. Es un vivir en lo concreto y en el hecho, no en la esencia. La objetividad es la esencia, el logos --Grecia y la Alemania intemporalLa vida es una unidad y división de la objetividad y la subjetividad. Pero dentro de esa unidad y división hay matices de objetividad o de subjetividad que no la destruyen. El vivir en el hecho y en lo concreto es la existencia anárquica. Los hechos son la mayor variabilidad, el hecho es, de suyo, lo indefinidamente distinto y fugaz. La fugacidad. El hombre latinoamericano no ha conocido la calma, no ha tenido sosiego, no ha o no había encontrado asidero. Es un hombre desalado. Viviendo en el hecho y en lo concreto no ha disfrutado de tradición. Ha carecido de ella. La tradición no es lo inmodificable o lo intemporal, lo estable o lo permanente. La tradición tiene un contenido y una función diversos. Es un conservar, superándose e integrándose. La tradición, insertándose en el pasado, no está vinculada inescindiblemente a él porque para ella el presente y el futuro no pueden ser una fiel reproducción del pasado. La tradición ha de justificar los cambios, las transformaciones - Inglaterra-. En Latinoamérica no ha habido tradición porque el hombre latinoamericano, al padecer el hecho, al sufrir lo concreto, ha sido incompatible con la tradición. He ahí el error de los partidos políticos que se dicen tradicionalistas en este continente. Defienden algo que no existe, que nunca ha existido, que sólo ahora y con frágil levedad va adquiriendo consistencia.

La subjetividad es la impresionabilidad. El hombre latinoamericano es impresionable. No tiene sentido crítico. Acepta, y acepta súbitamente, cualquier realidad cultural ya creada que se le ofrezca. En nuestra América la "novedad" es lo que impera en la esfera de la cultura. Lo nuevo se acepta inmediatamente. Hay movimientos intelectuales que se forman y desarrollan rápidamente y que en idéntica forma se extinguen. En el hombre latinoamericano la impresionabilidad es la carencia de toda capacidad creadora. Sólo había tenido capacidad para la imitación. No aprehende la realidad. No se coloca virilmente frente a ella para explicarla o comprenderla. Es un mirar la realidad al través de lo ya creado, al través de las concepciones del mundo y de la vida que llegan o llegaban a Latinoamérica enviadas por Europa." Nieto Arteta, Luis Eduardo. Hombre y cultura en Latinoamérica, Universidad Nacional de Colombia, No. 11, enero- abril, Bogotá, 1948, p. 223. 
su época. Por fortuna el optimismo histórico de que estaba imbuido, indudablemente fomentado por la visión que le había ofrecido el marxismo, le hizo vaticinar la necesaria superación de aquella supuesta nefasta situación (Nieto, 1948, p. 230). ${ }^{113}$

No le faltan razones a Damián Pachón para sostener que "Nieto Arteta realizó, antes que Sartre, una combinación de marxismo y fenomenología, tanto para sus estudios históricos como sociológicos" (Pachón, 2011, p. 148). Sin embargo, parece que no fue así en sus análisis propiamente filosóficos ya que en ellos se observa un significativo distanciamiento de las ideas marxistas. Tal vez Nieto pretendió realizar lo mismo que se había planteado el filósofo francés en su intento no de rechazar el marxismo, pues con razón consideraba que el marxismo sólo desaparecerá cuando desaparezcan las condiciones que lo propiciaron, sino por el contrario, de enriquecerlo y completarlo, pues a su juicio el marxismo carecía de una antropología filosófica, dado que el materialismo dialéctico sostenía que "mete al hombre en un baño de ácido sulfúrico" (Sartre, 1963, p. 38). De igual forma, el filósofo colombiano parecía tratar de articular el existencialismo y en general la filosofía de la vida con el marxismo al considerar que era insuficiente su análisis sobre la existencia individual humana, y no le faltaban ciertas razones fundamentadas para sostener esta tesis (Carta a Néstor Madrid-Malo, 1950). ${ }^{114}$ Pero a la vez esto pone de manifiesto una marcada inconsecuencia,

113 "El hombre latinoamericano se modificará inexorablemente. Nuevamente se impondrá la variabilidad histórica de la vida. Se realizará el tránsito a un mayor acento de objetividad. No desaparecerá la subjetividad. No podría extinguirse. Habrá una menor impresionabilidad La sensibilidad se amortiguará. Será la edad de la razón. Tendremos, al fin, tradición. Una tradición creadora y fecundante. Habrá continuidad en el desarrollo de la cultura. Seguiremos siendo emoción. Pero la emoción no es incompatible con los descubrimientos o las creaciones culturales. Contrariamente, sin emoción y sin asombro el hombre latinoamericano no podrá encontrar las esencias, las ricas y variadas esencias en los hechos y en las cosas.

Es una época que ya se ha iniciado. Vivimos esa zona obscura, contradictoria en la cual se une ella a la anterior jornada histórica. Somos unos hombres de un período de transición. Por eso, dudamos y titubeamos. Pero de la indecisión surgirá dialécticamente la afirmación creadora, el gozoso descubrimiento. Nieto Arteta, Luis Eduardo. Hombre y cultura en Latinoamérica, Universidad Nacional de Colombia, No. 11, enero- abril, Bogotá, 1948, p. 230.

114 "Pero el análisis no se debe limitar a la descripción sociológica de los supuestos históricos del existencialismo. Sería necesario mostrar la necesidad de descubrir las 
algo difícil de comprender, entre sus controvertidos enfoques y sus concepciones en el plano ontológico, antropológico, axiológico y epistemológico con sus metodológicos análisis en el terreno de las ciencias sociales en los que el marxismo en modo alguno está ausente.

Si bien el sociologismo vulgar - como criticaría Lenin a aquellos que tratan de descubrir detrás de cada tesis filosófica una postura de clases, como se observó en Althusser quien llegaría a reducir la filosofía a la lucha de clases en el terreno de las ideas (Guadarrama, 2007, pp. 61-77)_ podría conducir a pensar de manera exagerada que existe un nexo estrecho entre las mutaciones filosóficas y las ideológicas en Nieto Arteta, tampoco se deben descartar de forma total tales posibles imbricaciones.

Lo cierto es que trató a toda costa de argumentar desde la perspectiva marxista que los hechos históricos en modo algunos deben interpretarse como simples enfrentamiento entre elites que desconocen el protagonismo de las clases sociales y sus luchas. Esto se aprecia en la fundamentada crítica que realizó a aquellos historiadores soviéticos que trataron de presentar una nueva visión del devenir histórico latinoamericano (Nieto, 1978d, p. 215). ${ }^{115}$

peculiares contradicciones que se dan en la vida, en la vida tal como comprende el significado de esa palabra la filosofía contemporánea. Crear una filosofía de la vida como dialéctica regional de la vida. Ahora bien, en los autores marxistas contemporáneos no se encuentra esa descripción del peculiar contenido antinómico de la vida. Siguen aferrados al monismo naturalista del marxismo. Siguen haciendo del marxismo un sistema pétreo. Yo les pediría a los autores marxistas que acepten la necesidad de que haya diversas ontologías regionales. La filosofía de la vida será una de ellas". Carta a Néstor Madrid-Malo, Buenos Aires, 12 de noviembre de 1950.

115 "El sociólogo burgués Vilfrido Pareto, inspirador de Mussolini y de Jorge Sorel, extravió el criterio histórico de los miembros de la Academia de Ciencias de la Unión Soviética. Nuestros profesores no pudieron olvidar la muy conocida teoría de las elites sustentada por el egregio economista y sociólogo. Además, olvidaron que para un marxista no hay élites sino grupos sociales que disfrutan de hegemonía gubernamental y clases sociales cuyos intereses son defendidos por los respectivos Estados históricos que han existido. Por otra parte, las pugnas políticas en las repúblicas hispanoamericanas no son luchas internas dentro de unas élites feudales. Pintoresca inexactitud esa. Obtenida la independencia nacional se suscitó el siguiente problema: la conservación o la extinción de las instituciones y de las economías coloniales. Las jóvenes naciones debían resolver inicialmente ese tremendo problema al cual estaban subordinados todos los otros que planteaba la organización de los nacientes Estados. Eran antagónicos los intereses económicos de los grupos sociales que habían concurrido a sostener el movimiento de emanci- 
Ningún pensador, al igual que nadie en general, se deja influir de forma unilateral y exclusiva por las ideas de un solo pensador o de una específica corriente filosófica, que a su vez esta no haya sido conformada sobre los pilares de múltiples doctrinas.

La historia universal del pensamiento filosófico pone de manifiesto innumerables ejemplos de cómo pensadores de diversas épocas y circunstancias se han nutrido de múltiples fuentes en ocasiones aparentemente irreconciliablemente opuestas y han sabido conformar de manera auténtica propuestas antropológicas, epistemológicas, axiológicas, entre otras, no simplemente originales o novedosas, sino que han constituido verdaderos aportes al saber humano.

Ahora bien, tales procesos de recepción, transculturación, gestación y desarrollo de las ideas filosóficas no siempre se efectúan de manera artificial y ecléctica, sino de forma adecuadamente electivista - como fue propio de algunos de los jesuitas mexicanos del siglo xviII - retomando lo mejor de corrientes filosóficas anteriores y desarrollando propuestas propias acordes a los nuevos avances de las ciencias, las tecnológicas, las conquistas sociales, políticas, jurídicas, éticas, estéticas, entre otras, que los nuevos tiempos exigen y promueven. Sin embargo, esto no significa que se asuman indistintamente sin gradaciones valorativas las diferentes fuentes de alimentación teórica.

pación nacional. No todos esos grupos asumían la misma posición ante el problema que se ha explicado. Para los latifundistas no se debía eliminar la esclavitud. Si precisamente ellos cultivaban sus extensas y aun inexplotadas propiedades rurales utilizando el trabajo no libre de los esclavos. Igualmente, tampoco constituía para los latifundistas una traba desesperante en orden al desarrollo económico la conservación de los monopolios. El tabaco era cultivado por los campesinos libres en sus pequeñas parcelas. En los latifundios no se cultivaba la caña de azúcar. Sólo posteriormente, una vez obtenida la eliminación de la esclavitud, se inició ese cultivo en algunos latifundios. Los comerciantes y los artesanos deseaban la supresión de las instituciones coloniales - en estancos y gravosos impuestos-. No es erróneo declarar que en el siglo pasado las luchas y las guerras civiles fueron una expresión de la pugna irreductible entre los latifundistas (las comunidades religiosas poseían extensas propiedades) por una parte, y los comerciantes, los artesanos, los esclavos y los campesinos libres, por la otra. Tal es la significación de nuestras guerras civiles. Estas no correspondieron a las divergencias que se diesen dentro de unas élites feudales sino a la lucha de intereses económicos entre los grupos sociales que se han enumerado." Nieto Arteta. Luis Eduardo. "Una muy falsa historia de América (1946)," en Ensayos históricos y sociológicos, Instituto Colombiano de Cultura, Bogotá, 1978, p. 215. 
Siempre hay algunas que desempeñan un papel predominante y otras condicionantes, si bien en ocasiones se intercambian los roles entre ellas.

El caso de un inquieto intelectual de la talla de Luis Eduardo Nieto Arteta no podía constituir una excepción. Primero, en su época y ambiente intelectual y político era considerado el marxismo, con todas las limitaciones de fuentes y perspectivas sesgadas por la visión soviética de la época stalinista, una concepción del mundo, una ideología, una filosofía y específicamente un método dialéctico de análisis que le permitía adentrarse con mayor profundidad y objetividad en algunos de los entramados sustanciales de fenómenos históricos, económicos y sociales mundiales, latinoamericanos y colombianos, que la anteriormente predominante perspectiva positivista imperante en el ámbito cultural latinoamericano por su perspectiva empirista, reduccionista y fenomenalista no le permitía.

Una generación intelectual latinoamericana anterior a la suya había comenzado con éxito a desbrozar aquella maleza positivista que impedía comprender al ser humano en su multilateralidad vivencial, existencial, valorativa, entre otras, que tampoco el discurso marxista de la época le proporcionaba. Este le resultaba útil para el análisis de ciertas macroestructuras sociales, fuentes reales de la riqueza, relaciones de producción, interacciones socioclasistas, determinaciones de la política, y demás. Tal instrumentario metodológico no era aconsejable abandonarlo aun cuando fuese insuficiente para analizar de forma más integral la condición humana, en particular el ser humano latinoamericano y colombiano.

Por esa razón, buscó, tal vez de forma algo desorganizada, y encontró otras fuentes nutritivas en pensadores de segundo orden como Proudhon y Spengler en el orden propiamente filosófico, ya que en el terreno jurídico otros serían sus referentes, y en corrientes de la filosofía de su época como la filosofía de la vida, la fenomenología y el existencialismo algún asidero para una mejor comprensión de la conflictiva condición humana.

En esa labor, pareciera dejarse seducir en ocasiones por los cantos de sirena de nuevas modalidades mucho mejor elaboradas de idealismo filosófico, cuando afanosamente se da a la búsqueda de "dialécticas puras" y "ontologías regionales", entre otras. Sin embargo, la arraigada perspectiva materialista aflora una y otra vez en sus estudios sociales, aunque en ocasiones pareciesen muy distantes de sus disquisiciones filosóficas en persecución de conceptos esenciales. 
Otra cuestión constituyen sus decepciones y vaivenes ideológicos respecto al socialismo y el liberalismo que no han sido objeto del presente análisis, pero no por eso deben desestimarse, pues en alguna medida también permearon sus diferentes actitudes ante el marxismo.

Una vez más se confirma la hipótesis respecto a los grandes pensadores latinoamericanos (Dussel, Mendieta, Bohorquez, 2009) que se inscriben en lo mejor de la tradición humanista y desalienadora del pensamiento filosófico latinoamericano (Guadarrama, 1997), pero en este caso también de los estudios sociales, fundamentalmente en los terrenos de la economía y la historia. Con Nieto Arteta se podrá estar en acuerdo o desacuerdo, pero no es posible desconocer su rol en la trayectoria filosófica y científico social latinoamericana. Y se suma su clara ubicación dentro de la tradición del pensamiento marxista latinoamericano, independientemente de sus acercamientos y distanciamientos en diferentes planos, su obra en ese sentido resulta también, de algún modo, en beneficio de inventario de lo que comúnmente se debe reconocer como autenticidad (Guadarrama, 1999, p. 459) en la tradición del pensamiento marxista en Latinoamérica. 

Capítulo VIII

BIBLIOTECA

(1E COLOMBIANA 
